\title{
Telecommunications in Malaysia: diversity in adversity
}

\begin{abstract}
The telecommunications industry in Malaysia has experienced a tremendous transformation in just over a decade. The government-owned Jabatan Talikom, which hitherto operated the network, was incorporated in 1987 and subsequently privatized a few years later, with a majority share holding by the government. The regulatory aspects were spun off under the slim looking JTM. This marked the beginning of liberalization, and many new players entered the fray. This article reviews the telecommunications infrastructure and services available in Malaysia and briefly visits some of the telcos offering these services. Some pertinent issues affecting the industry are also discussed.
\end{abstract}

Keyword: Telecommunications; Malaysia; Telecommunication industry; Telecommunications infrastructure and services 